\title{
Impact of Urban Compactness on Carbon Emission Efficiency in Small Towns in China
}

\begin{abstract}
Qing YUAN, Ran GUO, School of Architecture, Harbin Institute of Technology; Key Laboratory of Cold Region Urban and Rural Human Settlement Environment Science and Technology, Ministry of Industry and Information Technology; China
\end{abstract}

\begin{abstract}
Maintaining a balance between economic development and carbon emissions reduction is an important part of low-carbon development in modern cities. At present, the positive effect of urban compactness on carbon emission efficiency has been demonstrated in large cities, but few studies have been carried out on small towns. Small towns are an important part of China's urban system, accounting for $70 \%$ of the total population and $60 \%$ of the national GDP. Most small towns in China still promote economic growth and enhance the social welfare of residents by large-scale urban construction, which inevitably leads to urban expansion and high carbon emissions. How to reduce carbon emissions by optimising urban form while continuing with economic development and maintaining people's welfare has become an important issue faced by small towns in China. To guide the low-carbon planning of small towns, it is necessary to understand the relationship between urban compactness and the economic benefit and socialwelfare levels associated with the carbon emissions in small towns. This study quantitatively analyse the relationship between urban compactness and carbon emission efficiency (including CO2 economic efficiency and CO2 social efficiency) in small towns in the Yangtze River Delta (YRD) from 2008 to 2017. This study resulted in four main findings. (i) the expansion of urban scale had significantly improved the $\mathrm{CO} 2$ economic efficiency and $\mathrm{CO} 2$ social efficiency; (ii) the compactness presented opposite effects on the $\mathrm{CO} 2$ economic efficiency and $\mathrm{CO} 2$ social efficiency, compactness had a negative correlation with $\mathrm{CO} 2$ economic efficiency, and had a positive correlation with $\mathrm{CO} 2$ social efficiency; (ii) The CO2 economic efficiency and $\mathrm{CO} 2$ social efficiency both show an upward trend over the period 2008 to 2017; (iv) The relationship between GDP and carbon emissions in small towns did not reach an ideal state, the economies of small towns in China are still strongly dependent on scale expansion.
\end{abstract}

\section{Keywords}

CO2 Emission Efficiency, Spatial Form of Town, Landscape Metrics, Stepwise Regression Analysis, Low-carbon Planning

\section{Introduction}

The increasingly prominent energy constraints and severe environmental degradation have made lowcarbon development an inevitable choice to cope with energy shortage and achieve environmental friendliness, and at the same time forced carbon benefits to shift from the simple pursuit of economic growth targets to the comprehensive quality of economic and social development. Therefore, balancing the relationship between the level of economic and social development and carbon emissions, and seeking the maximization of economic benefits and social welfare at a lower level of carbon emissions, has turned into an objective requirement for regional low-carbon development. 
China is currently in the middle stage of urbanization. County towns accommodate about $75 \%$ of China's population and create more than half of its total economic aggregate. They are the the most basic units for China to achieve low-carbon development and regional balanced development. The large-scale expansion of urban population and the massive construction of urban roads and other infrastructure have significantly increased greenhouse gas emissions. A large number of studies have confirmed that urban form has a great effect on carbon emission efficiency. Among them, the compact form is considered to be effective in improving the level of urban carbon emission efficiency. Compared with the sprawling urban form, the compact urban form refers to the layout of high-density industries and population in the limited urban space, which is characterized by high-density and compact functions. Some empirical studies have indicated that a more compact urban form is more conducive to reducing $\mathrm{CO} 2$ emissions, especially by promoting mixed land use, reducing carbon emissions from transportation and buildings, and improving the utilization efficiency of urban public facilities and infrastructure. However, some studies have gradually found that compact and centralized policies are not a sustainable model for achieving urban $\mathrm{CO} 2$ reduction. At present, empirical studies on the relationship between compact urban form and carbon emission efficiency mostly remain at metropolises, the research on the rapid development of small towns in China remains extremely limited.

Since urban form is a complex and pluralistic concept that each study has different index selection and measurement methods based on different understanding. Some studies focus on statistical data indicators such as urban scale, population and land use to measure urban form; some studies select landscape metrics to measure urban form. The landscape metrics mainly measures the shape and distribution pattern of plaques in the landscape pattern when characterizing the urban form. In recent years, with the rapid development of remote sensing and geographic information technology, this method has gradually turned into an effective way to analyze urban form in the related research of carbon emission efficiency.

In terms of carbon emission efficiency, the existing studies on the relationship between compact urban forms and carbon emission efficiency mostly focus on the $\mathrm{CO} 2$ economic efficiency. Related research suggests that the impact of compact urban form on the $\mathrm{CO} 2$ economic efficiency mainly changes economic performance by changing the type of land use, or by affecting the economic development environment such as regional agglomeration effect and scale effect. In addition, an increasing number of studies have begun to pay attention to the role of the compact spatial form in improving the $\mathrm{CO} 2$ social efficiency. The carbon emission efficiency is a comprehensive conception of the intrinsic value of carbon emissions in the process of urban development, including all monetary and other benefits related to carbon emissions. It can be divided into economic benefits and social welfare. In recent years, the ratio of human development index and carbon emissions based on the comprehensive living conditions of residents has become an important way to measure the $\mathrm{CO} 2$ social efficiency.

This study aims to explore the impact of compact urban form on carbon emission efficiency. Taking the 10 small towns in the Yangtze River Delta in the past decade (2008-2017) as the research objects. This paper used remote sensing data and landscape metrics to quantify the compactness of urban form, and used the human development index and low-carbon economic index to comprehensively calculate carbon emission efficiency. The stepwise regression model between urban compactness and carbon emission efficiency quantified the relationship between the urban form of small towns in the county and the $\mathrm{CO} 2$ economic efficiency and $\mathrm{CO} 2$ social efficiency. This study provided empirical cases and useful reference for the sustainable development of small towns in county regions in China at the present stage. 


\section{Method}

\subsection{Overview of the study area}

Ten county towns (Changshu, Cixi, Haining, Jiangyin, Rugao, Taicang, Yixing, Yiwu, Zhangjiagang and Changxing) in the Yangtze River Delta (YRD) of China have been selected as the research objects (Fig. 1). The Yangtze River Delta is located in the east coast of China, covering two provinces (Zhejiang Province, Suzhou Province) and a municipality directly under the central government (Shanghai), with a total area of $210,700 \mathrm{~km} 2$ (Figure 1), including 25 cities and 92 county-level small towns. These small towns are all on the list of Top 100 Counties in China (China National Bureau of Statistics) from 2008 to 2017, which comprehensively takes into account the development level, development vitality and development potential of small towns. At the same time, the urbanization rate, GDP, per capita disposable income, educational resources, transportation infrastructure and political importance of the 10 small towns are all in the forefront of the province. In addition, the expansion of urban construction land and the phenomenon of population mobility are significant in recent years. Therefore, this study selects these ten small towns as the representative of small and medium-sized towns in China's rapid urbanization process.

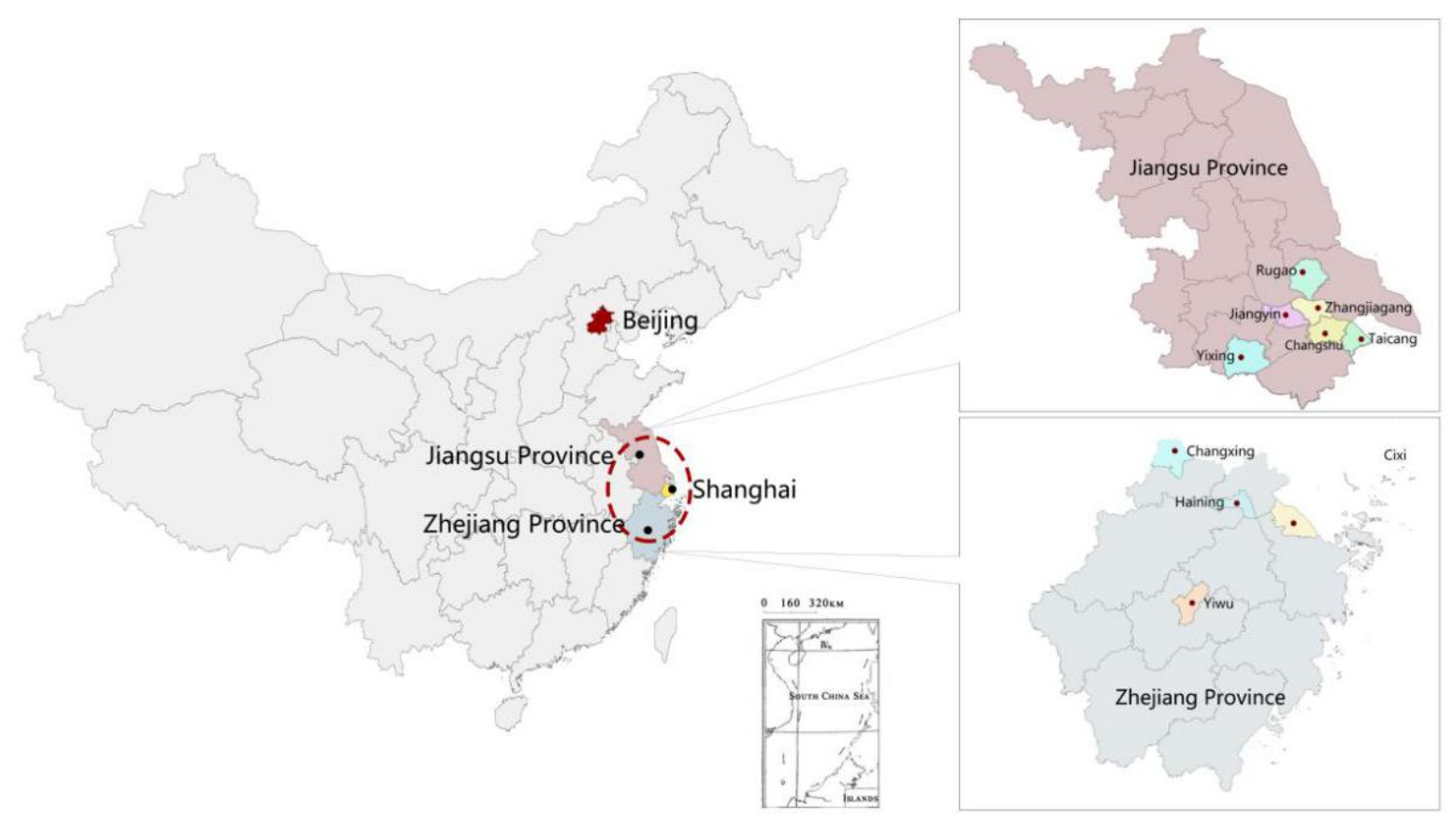

Figure1. Location of the study areas. Source: drawn by authors.

\subsection{Quantification of urban form}

In this study, the remote sensing image data of the American land satellites Landsat4-5 TM and Landsat8 OLI are used as the main data sources to quantify the urban form. The images of 2008, 2011, 2014 and 2017 are extracted and interpreted at a time interval of 2 years. The remote sensing image of ENVI5.3 software is utilized for image interpretation. Based on the interpretation of urban construction land, the characteristics and evolution trend of urban forms are explored by comparing the changes of landscape metrics in time series. In this paper, total area (CA), patch cohesion index (COHESION), aggregation index (AI) and contiguity index (CONTIG) are selected to describe the compactness of towns. The specific quantitative results are calculated by FragStats 4.2. 


\subsection{Carbon emission efficiency calculation}

The $\mathrm{CO} 2$ economic efficiency is a measure of $\mathrm{CO} 2$ emissions utilized for economic development. It is quantified by the ratio of economic performance to total carbon emissions (Eq. (1)).

$$
\mathrm{CEE}=\frac{\mathrm{GDP}}{\mathrm{CE}}
$$

where CEE stands for CO2 economic efficiency, CE stands for the total carbon emission (10,000 tons), and GDP stands for regional GDP (100 million yuan).

The $\mathrm{CO} 2$ social efficiency is a measure of $\mathrm{CO} 2$ emissions utilized for non-economic development, which is quantified by the ratio of social development performance to total carbon emission (Eq. (2)).In this paper, the Human Development Index (the United Nations Development Program, UNDP) is selected as the core index to evaluate the performance of social development. The index is a composite of three individual indicators of health, education and living standard (Eq. (3)).

$$
\begin{aligned}
\mathrm{CSE} & =\frac{\mathrm{HDI}}{\mathrm{CE}} \\
\text { where, } \mathrm{HDI} & =\sqrt[3]{\mathrm{HI} \cdot \mathrm{EI} \cdot \mathrm{II}}
\end{aligned}
$$

where CSE represents CO2 social efficiency; HDI represents social development performance; HI represents health index; El represents education index; and II represents living standard index.

\subsection{Correlation analysis}

The stepwise regression method is utilized to quantify the impact of urban form on carbon emission efficiency. Taking the landscape metrics as the independent variable of the regression model, and the carbon emission efficiency in 2008, 2011, 2014 and 2017 as the dependent variable, forward stepwise regression analysis are carried out. The landscape metrics that have significant impacts on carbon emission efficiency are identified, and the quantitative relationship between them are determined. Each time an independent variable is introduced into the model, the previously introduced independent variables are re-tested until the selected independent variables are all significant, thereby establishing a series of multiple linear regression equations containing different landscape metrics variables. The most reasonable stepwise regression analysis models will be ultimately determined according to different critical values of $F$ test (introduction and elimination factor test), and the regression coefficient of the selected variables, corresponding decision coefficient $\left(R^{2}\right)$ and $P$ value will be obtained.

\section{Results and Discussions}

\subsection{The characteristics of urban form}

Due to the acceleration of urbanization, the urban form of the 10 small towns had undergone tremendous changes from 2008 to 2017 (Figure 2). Overall, the total area of small towns had grown rapidly, the land use had undergone major changes, and the scale of towns had expanded rapidly. In 2008, the largest small town Jiangyin and the smallest small town Haining had an area of $403 \mathrm{KM}^{2}$ and $185.3 \mathrm{KM}^{2}$ respectively. By 2017, the largest and smallest towns were Yixing and Haining, with an area of $573.5 \mathrm{KM}^{2}$ and $284.9 \mathrm{KM}^{2}$ respectively. In the 10 years from 2008 to 2017, the largest area change in the 10 small towns was Yixing with an increase of $122 \%$, while the smallest was Changshu with an increase of only $1.5 \%$, and the area of 10 small towns increased by $49.4 \%$ on average. 
(a) Changshu, CS

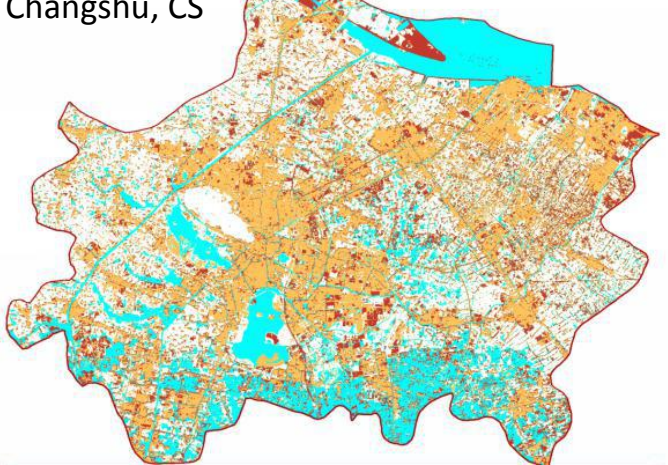

(c) Haining, $\mathrm{HN}$

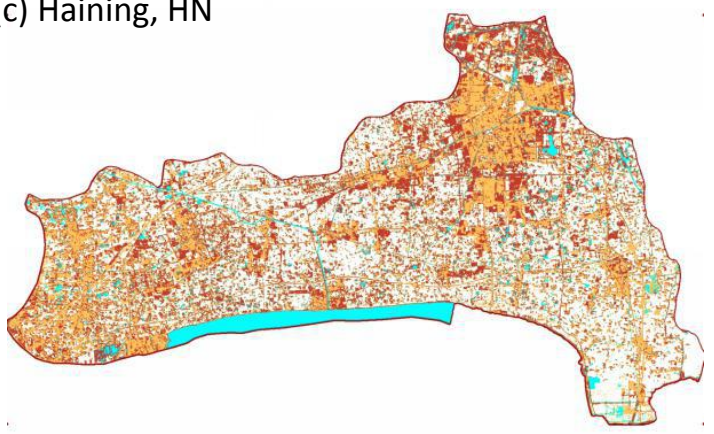

(e) Rugao, RG

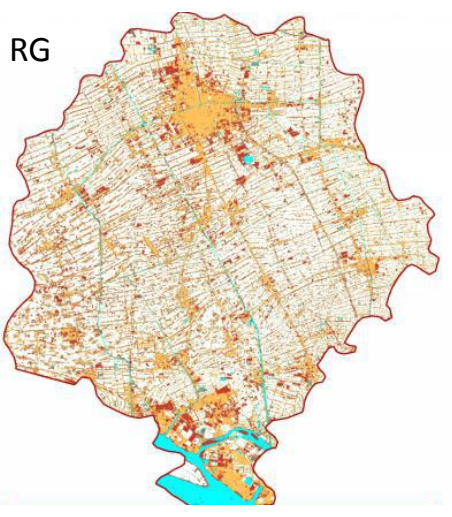

(g) Yixing, YX

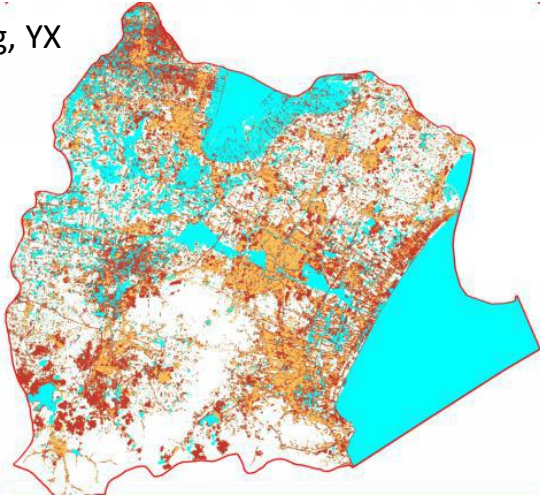

(b) Cixi, CX

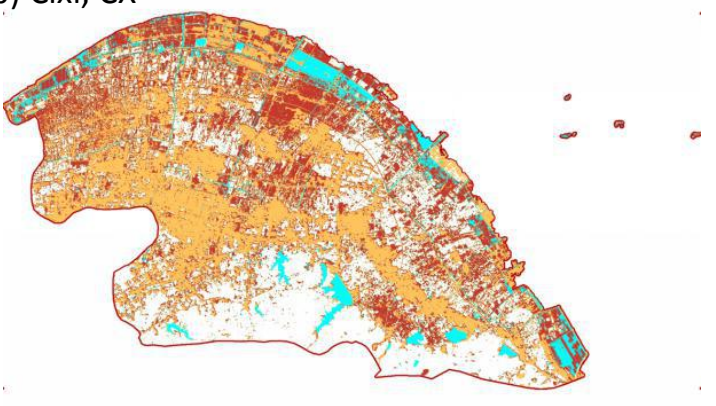

(d) Jiangyin, JY

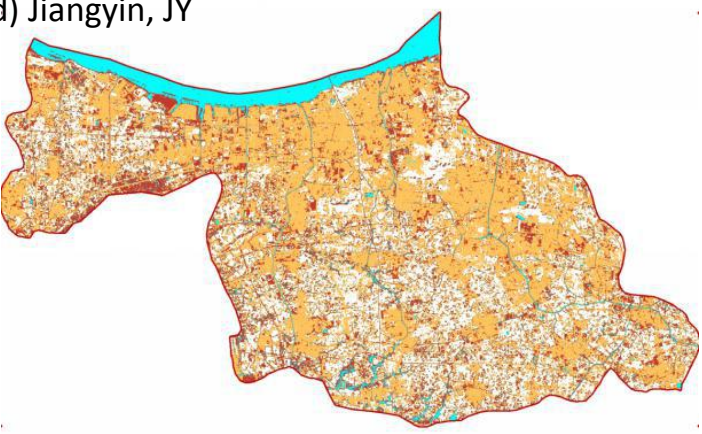

(f) Taicang, TC

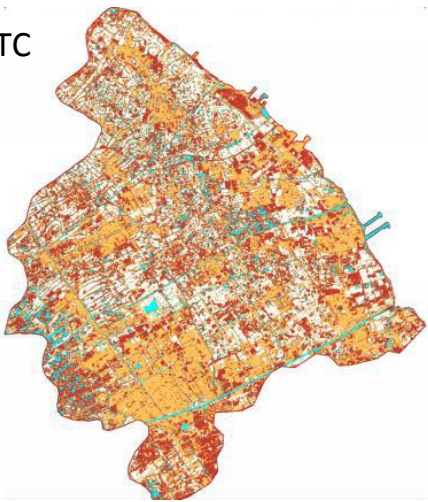

(h) Yiwu, YW

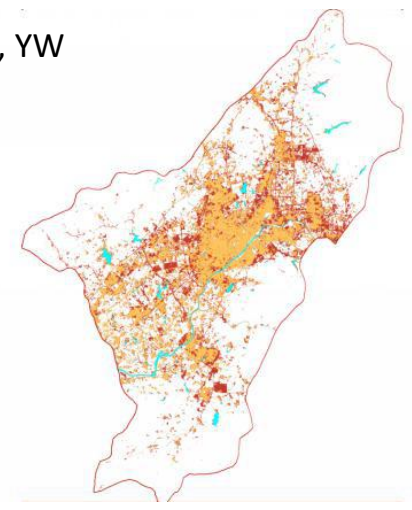




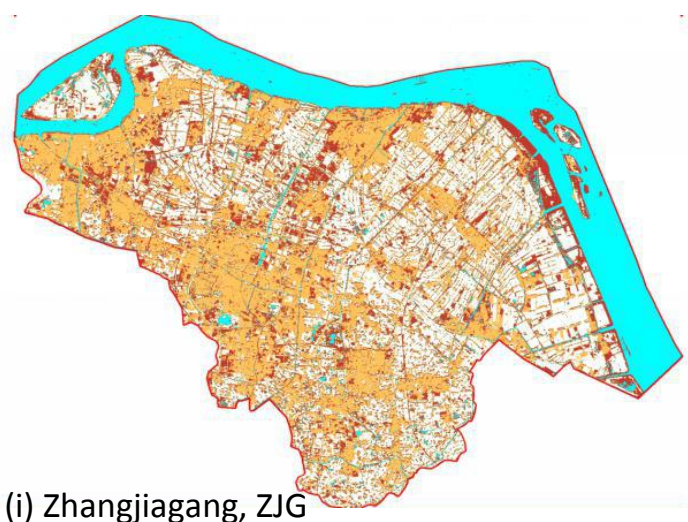

(j) Changxing, $\mathrm{CHX}$

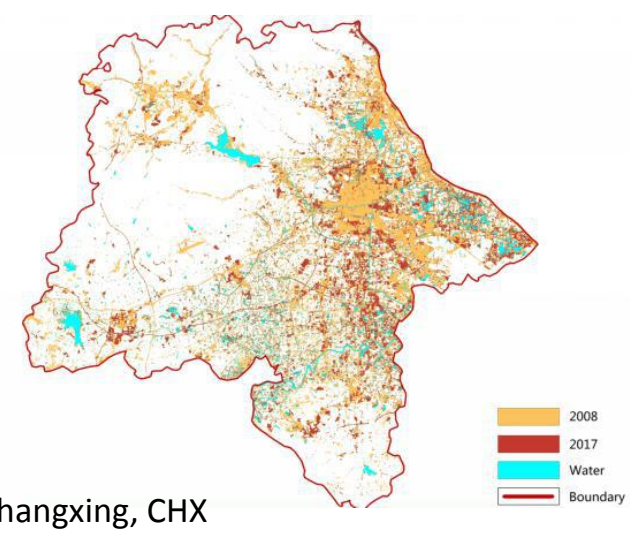

Figure 2. Changes in remote sensing image of urban form in Changshu (a), Cixi (b), Haining (c), Jiangyin (d), Rugao (e), Taicang (f), Yixing (g), Yiwu (h), Zhangjiagang (i) and Changxing (j), 2008/2017. Source: drawn by authors.

The calculation results of the three indexes of COHESION, AI, and CONTIG indicated that in terms of the size of the indexes, there were differences between small towns, but the basic trend of change was the same. Among these 10 small towns, the COHESION, Al, and CONTIG of the four small towns including Yixing showed increasing trends to varying degrees during the study period, indicating that the rapid development of urbanization had generally improved the proximity between the construction land patches in these four areas, and the increase in Al indicates that the urban central area had gradually formed scale and tended to be obvious, and the overall compactness increased.

\subsection{The characteristics of carbon emission efficiency}

During the study period, the changes of CEE and CSE in these 10 small towns are shown in Figure 3 and Figure 4. In terms of the overall trend, each index showed an upward trend with an obvious increase, indicating that the contribution rate of the same amount of carbon emissions to GDP and social development was gradually increasing and developing towards a low-carbon economy. As for the CSE, except Rugao, which showed a downward trend, the other 9 small towns all show fluctuating upward trends. In addition, the longitudinal comparison of the starting and ending years showed that in 2008 , the CEE of these 10 small towns ranged from 0.73 to 1.02, and by 2017, the range of economic benefits of carbon emissions had increased to1.31 to 1.74. The range of CEE also increased from 0.02 to 1.23 in 2008 and inceased to 0.27 to 1.47 by 2017 . Among the ten small towns, Taicang and Yiwu were the fastest growing ones in terms of economic and CSE, which were in a better state of low-carbon development at the present stage.

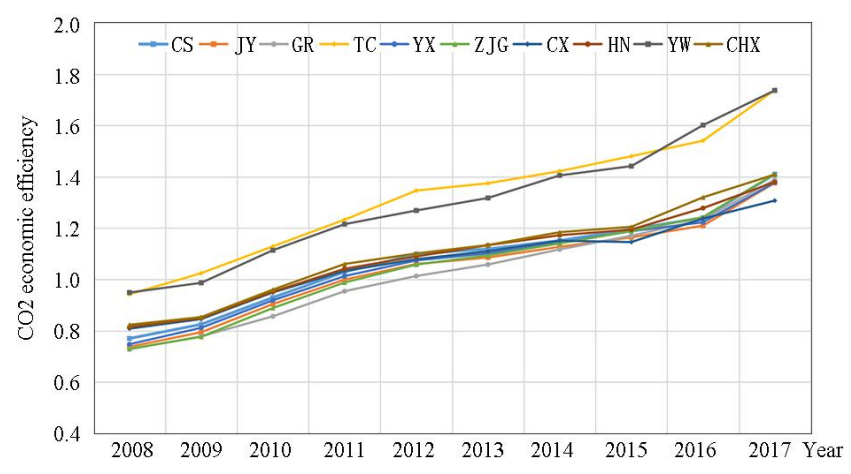

Figure 3. CO2 economic efficiency (CEE), 2008-2017. Source: drawn by authors. 


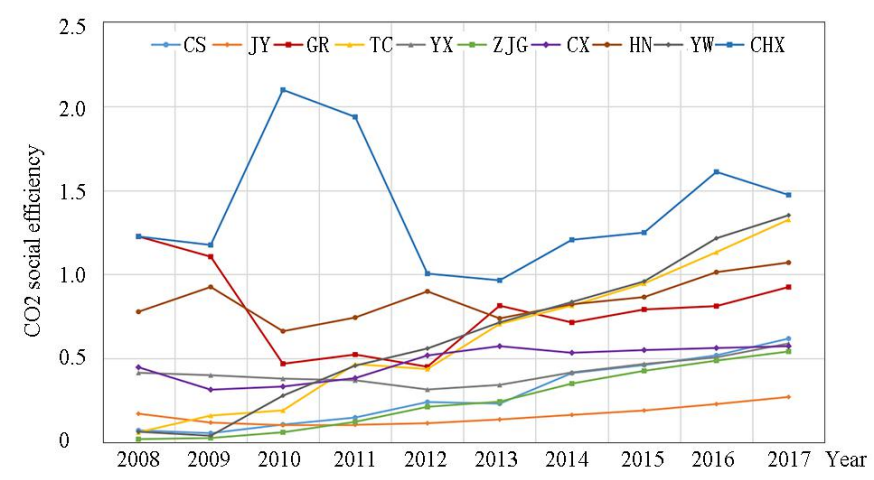

Figure 4. CO2 social efficiency (CSE), 2008-2017. Source: drawn by authors.

\subsection{The characteristics of carbon emission efficiency}

As shown in Table 1, in 2008-2017, among the 10 research objects, the CA of 6 small towns had a significant correlation with the economic benefits of urban carbon emissions, and the correlation coefficients were all positive. This indicated that the expansion of urban scale was an important factor to promote GDP growth. Regression models were constructed based on the results of correlation analysis (Table 2). The R-square of the six regression models was in the range of 0.920 to 0.996 , and all of them passed the independent sample t test, indicating that the goodness of fit of regression equations was good and the model results were repeatable. The regression coefficients of the CA to the CEE were positive, indicating that the CEE would increase to a certain extent with the increase of total patch area. In other words, in the current stage of development, the increase of construction land and the sustainable development of real estate are still the important sources of economic growth of small towns, and the expansion of spatial form of small towns is beneficial to the promotion of carbon efficiency.

Table 1. Pearson Correlation between CA and CEE. Source: drawn by authors.

\begin{tabular}{lllllll}
\hline \multicolumn{2}{c}{ ZJG } & YW & TC & RG & CX & HN \\
\hline Pearson Correlation & $.962^{*}$ & $.959^{*}$ & $.998^{* *}$ & $.982^{*}$ & $.966^{*}$ & $0.937^{*}$ \\
*. Correlation is significant at the 0.05 level (2-tailed). & & & & \\
**. Correlation is significant at the 0.01 level (2-tailed). & & & & \\
\hline
\end{tabular}

Table 2. Regression Results of CA and CEE. Source: drawn by authors.

\begin{tabular}{lrrrrrr}
\hline & \multicolumn{2}{c}{ ZW } & TC & RG & CX & HN \\
\hline Constant & -1.729 & -0.315 & -0.254 & -0.85 & -0.096 & -0.687 \\
Regression Coefficients & 0.00007804 & 0.00006176 & 0.00005194 & 0.0000547 & 0.0000415 & 0.00006528 \\
R Square & 0.926 & 0.920 & 0.996 & 0.964 & 0.933 & 0.945 \\
t-test (sig) & 0.000 & 0.001 & 0.000 & 0.000 & 0.000 & 0.000 \\
\hline
\end{tabular}

The CA of five small towns had a significant correlation with the social benefits of urban carbon emissions, and the correlation coefficient were also positive (Table 3). Regression models were constructed based on the results of correlation analysis (Table 4). The R-squares of the five regression models were in the range of 0.904 to 0.992 , and all of them passed the independent sample $t$ test, indicating that the goodness of fit of regression equations was good and the model results were repeatable. The regression coefficient of CA to CEE was positive, which indicated that with the increase of total patch area, the expansion of urban scale could effectively improve the level of social welfare of residents. To a certain extent, through the further efficient and reasonable arrangement of public service facilities such as hospitals and schools, the life expectancy, average education years and expected years of education of residents can be increased. In addition, the expansion of urban scale will also have a positive impact on 
the income level of residents by improving the overall economic agglomeration effect of the region, so as to improve the level of social well-being of residents.

Table 3. Pearson Correlation between CA and CSE. Source: drawn by authors.

\begin{tabular}{|c|c|c|c|c|c|}
\hline & YW & $\mathrm{TC}$ & ZJG & RG & $C X$ \\
\hline Pearson Correlation & $.951^{*}$ & $.996 * *$ & $.962 *$ & $.953^{*}$ & $.946^{*}$ \\
\hline
\end{tabular}

Table 4. Regression Results of CA and CSE. Source: drawn by authors.

\begin{tabular}{lrrrrr}
\hline & TW & ZJG & RG & CX \\
\hline Constant & -2.017 & -1.878 & -1.956 & -0.985 & -1.532 \\
Regression Coefficients & 0.00010139 & 0.00008328 & 0.00009523 & 0.00008652 & 0.00010025 \\
R Square & 0.904 & 0.992 & 0.952 & 0.985 & 0.974 \\
t-test (sig) & 0.000 & 0 & 0.001 & 0.000 & 0.000 \\
\hline
\end{tabular}

As shown in Table 5, the impact of compactness on CSE were relatively complex, and its impact on CEE and CSE showed opposite results. Compactness had a negative correlation with CEE, and had a positive correlation with CSE. Specifically, for the CEE, the correlation analysis results of six small towns, such as ZJG, show that COHESION, Al and CONTIG had obvious correlation with CEE. The results of VIF showed that there were multicollinearity among these three indexs (Table 6). Therefore, stepwise regression method was used to eliminate the non significant influence variables. Stepwise regression results showed that in ZJG, JY, HN and CS, CONTIG and AI were significant variables, and COHESION was excluded from the model; in TC and CX, AI was significant variable, while CONTIG and COHESION were excluded (Table 7).

Table 5. Pearson Correlation between COHESION, AI, CONTIG and CEE. Source: drawn by authors.

\begin{tabular}{|c|c|c|c|c|c|c|}
\hline & ZJG & $\mathrm{TC}$ & JY & $\mathrm{HN}$ & $C X$ & $\mathrm{CS}$ \\
\hline COHESION & $-.927^{*}$ & $-.958 *$ & $-.986 *$ & $-.943^{*}$ & $-.926^{*}$ & $-.964 *$ \\
\hline $\mathrm{Al}$ & $-.987^{*}$ & $-.945^{*}$ & $-.953^{*}$ & $-.954 *$ & $-.938^{*}$ & $-.975^{*}$ \\
\hline CONTIG & $-.977^{*}$ & $-.997^{*}$ & $-.942 *$ & $-.955^{*}$ & $-.946 *$ & $-.983^{*}$ \\
\hline
\end{tabular}

Table 6. VIF Results of COHESION, Al and CONTIG. Source: drawn by authors.

\begin{tabular}{ll}
\hline & VIF \\
\hline COHESION & 12.56 \\
Al & 11.25 \\
CONTIG & 10.68 \\
\hline
\end{tabular}

Table 7. Regression Results of COHESION, AI, CONTIG and CEE. Source: drawn by authors.

\begin{tabular}{lllllll}
\hline & ZJG & TC & JY & HN & CX & CS \\
\hline Constant & 4.247 & 3.586 & 4.265 & 5.019 & 6.253 & 2.823 \\
Regression Al & -0.009 & -0.011 & -0.006 & -0.007 & -0.018 & -0.012 \\
Coefficients CONTIG & -15.143 & - & -10.965 & -16.496 & - & -7.471 \\
R Square & 0.955 & 0.941 & 0.956 & 0.912 & 0.925 & 0.967 \\
t-test (sig) & 0.000 & 0.000 & 0.000 & 0.000 & 0.000 & 0.000 \\
\hline
\end{tabular}


For the CSE, the three indexes are significantly correlated in five small towns (Table 8). The results of stepwise regression showed that in ZJG, YX and $\mathrm{CHX}$, Al was a significant variable and retained in the model, and CONTIG and COHESION were eliminated; in YJ and CS, CONTIG was a significant variable, retained in the model, $\mathrm{Al}$ and COHESION were eliminated (Table 9).

Table 8. Pearson Correlation between COHESION, AI, CONTIG and CSE. Source: drawn by authors.

\begin{tabular}{llllll}
\hline & ZJG & YX & JY & CX & CS \\
\hline COHESION & $.986^{*}$ & $.956^{*}$ & $.897^{*}$ & $.984^{*}$ & $.897^{*}$ \\
Al & $.865^{*}$ & $.845^{*}$ & $.865^{*}$ & $.997^{* *}$ & $.964^{*}$ \\
CONTIG & $.846^{*}$ & $.985^{*}$ & $.912^{*}$ & $.932^{*}$ & $.986^{*}$ \\
*. Correlation is significant at the 0.05 level (2-tailed). & & & \\
**. Correlation is significant at the 0.01 level (2-tailed). & & & \\
\hline
\end{tabular}

Table 9. Regression Results of COHESION, AI, CONTIG and CSE. Source: drawn by authors.

\begin{tabular}{|c|c|c|c|c|c|}
\hline & ZJG & $\mathrm{YX}$ & JY & $C X$ & CS \\
\hline Constant & -3.658 & -2.865 & 3.71 & -2.464 & 1.95 \\
\hline Regression Al & 0.064 & 0.041 & - & 0.035 & - \\
\hline Coefficients CONTIG & - & - & 8.512 & - & 7.056 \\
\hline R Square & 0.942 & 0.938 & 0.915 & 0.994 & 0.973 \\
\hline t-test（sig） & 0.000 & 0.000 & 0.000 & 0.000 & 0.000 \\
\hline
\end{tabular}

Generally speaking, although the impact trend and degree of compactness and CEE are not completely consistent, the basic performance is that the compactness has a positive correlation with the CEE, and has a negative correlation with the CSE. In other words, the increase of compactness will lead to the promotion of the CEE and the decrease of the CSE.

\section{Conclusion}

Based on the data of 10 county towns from 2008 to 2017, this paper measures the compactness of urban form with landscape metrics, and makes an empirical study on the impact of compactness on the evolution of carbon emission efficiency. The results showed that in the past decade, the expansion of urban scale had significantly improved the CEE and CSE; the compactness presented opposite effects on the CEE and CSE. Therefore, based on the above research results, this paper holds that in the current development stage of China, for the new low-carbon city development goals aiming at improving urban carbon emission efficiency, the best urban development mode should firstly encourage the moderate expansion of urban scale while preventing the disorderly spread of space; secondly, the compactness of urban functional space should be strengthened and the development mode of dense proximity should be advocated.

At present and for a long period of time in the future, land finance remains an important part of the economic growth of small towns in China. It not only provides security for the development of national economy, but also contributes to the development of local industrial economy, population and society. Although the expansion of urban form promotes the improvement of carbon emission efficiency in small towns, a large number of practices and research results show that large-scale and disorderly land development will have a significant negative impact on energy consumption, carbon emissions and corresponding carbon emission efficiency. Therefore, for the small towns in county regions at the present stage, it can be considered to predict the future urban population size according to the number of permanent residents, determine the standard of infrastructure allocation, and reasonably determine the urban scale; limit the supply of residential land according to the actual residential demand, thereby 
controlling the gradual "residential" trend in the peripheral areas of cities and towns. In addition, the housing demand of the urban affluent class in China is biased towards large-sized units, and the imbalance in housing distribution has led to the low residential density in China, which has led to the irrational distribution of urban forms and the rise of carbon emissions. Therefore, encouraging lowcarbon and economical residential consumption mode can also achieve effective improvements of carbon emission efficiency through rational allocation of housing.

The compact spatial development strategy plays a positive role in improving the CEE in counties and towns, and has a negative impact on the CSE. Based on the spatial characteristics of county towns, on the one hand, this paper proposes to improve the scale effect of urban central area, strengthen the urban central area composed of commerce, entertainment, culture, etc., thereby meeting the diverse needs of residents, and reducing the frequency of travel and carbon emissions. On the other hand, intensive and adjacent development models are encouraged. Through the redevelopment of inefficient land such as brownfield, the reuse of vacant buildings, or the use of stock or reduction planning, the compactness of urban functional space can be improved, and the existing infrastructure and service facilities will be fully utilized. The CEE will be enhanced by improving accessibility and reducing energy consumption in the transportation sector. At the same time, it is also necessary to be wary of the pressure on traffic flow caused by excessive building density in the central area, which may lead to traffic congestion and increase in carbon emissions, thereby adversely affecting the carbon effect.

On addition, future studies can further adjust the screening criteria and basis for the small towns of the research object, increase the sample, and better explore the relationship between the compactness of small towns and carbon emission efficiency under different location conditions.

\section{Acknowledgements}

This research was financially supported by the China National Key R\&D Program during the 13th Five-year Plan Period (Grant No. 2018YFC0704705).

\section{References}

Brockmann H., Delhey J., Welzel C., et al. (2009) 'The China Puzzle: Falling Happiness in a Rising Economy', Journal of Happiness Studies, 10(4), p387-405.

Chinese National Bureau of Statistics. (2017) China County Statistical Yearbook. Beijing: China Statistics Press.

Shaojian W, Jieyu W, Chuanglin F, et al. (2018) 'Estimating the impacts of urban form on CO2 emission efficiency in the Pearl River Delta, China', Cities.

Shijie L, Chunshan Z, Shaojian W, et al. (2018) 'Dose urban landscape pattern affect CO2 emission efficiency? Empirical evidence from megacities in China', Journal of Cleaner Production, 203(PT.11216), p164-178.

Yanchun Y, Sisi M, Weijun G. (2018) 'Are compact cities low-carbon?’, City Planning Review, p31-38.

Huanzhao Z, Shouyi H. (2008) 'Urban Space Expansion and Land Intensive Utility', Economic Geography, 2008(3),p419-424.

Sunsheng H, Bo Q. (2009) 'The Compact City and Sustainable Urban Development in China', Urban Planning International, 24(S), p263-268. 
Bereitschaft, B., Debbage, K.. (2013) 'Urban form, air pollution, and CO2 emissions in large u.s. metropolitan areas', Professional Geographer, p65(4).

Shaojian W, Xiaoping L, Chunshan Z, et al. (2017) 'Examining the impacts of socioeconomic factors, urban form, and transportation networks on CO2 emissions in China's megacities', Applied Energy, p185.

Kahn, M. E. (2004) 'Chapter 56 sprawl and urban growth', Handbook of Regional \& Urban Economics, p2481-2527.

Paolo V. (2010) 'Urban Polycentricity and the Costs of Commuting: Evidence from Italian Metropolitan Areas', Growth and Change, p41(3).

Sharifi A, Chiba Y, Okamoto K, et al. (2014) 'Can master planning control and regulate urban growth in Vientiane, Laos?', Landscape \& Urban Planning, p131: 1-13.

Galster G, Hanson R, Ratcliffe R M, et al. (2001) 'Wrestling sprawl to the ground: Defining and measuring an elusive concept', House Policy Debate, p12(4): 681-717.

Holden E, Norland I T. (2005) 'Three challenges for the compact city as a sustainable urban form: Household consumption of energy and transport in eight residential areas in the greater Oslo region', Urban Studies, p42(12): 2145-2166.

Geoghegan J, Wainger L A, Bockstael N E. (1997) 'Spatial landscape indices in a hedonic framework: An ecological economics analysis using GIS', Ecological Economics, p23(3): 251-264.

Parker D C, Meretsky V. (2004) 'Measuring pattern outcomes in an agentbased model of edge-effect externalities using spatial metrics', Agriculture Ecosystems \& Environment, p101(2-3): 233-250.

Herold M, Scepan J, Clarke K C. (2002) 'The use of remote sensing and landscape metrics to describe structures and changes in urban land uses', Environment and Planning A, p34(8): 1443-1458.

Zhenqi C, Xiongbin L, Li L, et al. (2016) 'Does Urban Spatial Morphology Affect Carbon Emission?: A Study Based on 110 Prefectural Cities', Ecological Economy, p32(010):22-26.

Lei Y, Guicai L, Yaoyu L, et al. (2011) 'Progress and Prospect on Relationship Research between Urban Form and Carbon Emission', urban studies, p18(02):12-17+81.

Ke Z, Tang-qi X, An-lu Z. (2016) 'Urban Land Expansion, Economies of Scale and Quality of Economic Growth', Journal of Natural Resources, p31(003):390-401.

Tahara K, Sagisaka M , Ozawa T, et al. (2005) 'Comparison of "CO2 efficiency" between company and industry', Journal of Cleaner Production, p13(13-14):1301-1308.

Jiahua P. (2002) 'A Conceptual Framework for Understanding Human Development Potential-With Empirical Analysis of Global Demand for Carbon Emissions', Social Sciences in China, p(06):15-25. 